\title{
Cinco textos de teatro
}

\section{Sara Figueiredo Costa}

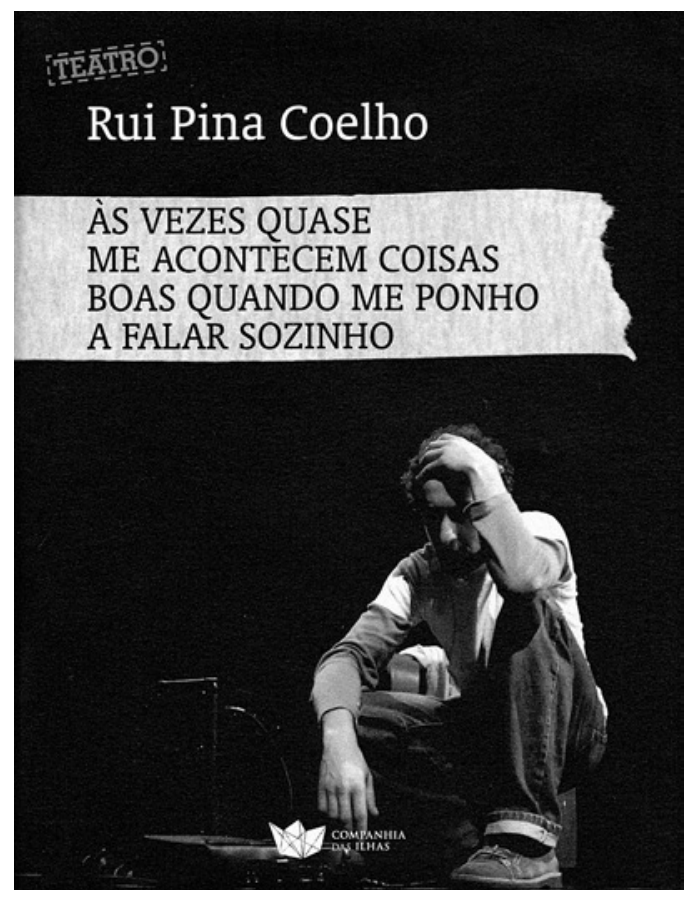

Pedro Eiras, Bela Dona e Outros monólogos, Lajes do Pico, Companhia das llhas, col. Azulcobalto/teatro, n. ${ }^{\circ} 1,1^{\text {a }}$ ed. $2012,2^{\text {a }}$ ed. 2013. $48 \mathrm{pp}$.

Rui Pina Coelho, Às vezes quase me acontecem coisas boas quando me ponho a falar sozinho, Lajes do Pico, Companhia das llhas, col. Azulcobalto/teatro, n. $^{\circ}$ 2, 2013, $40 \mathrm{pp}$.

Jaime Rocha, $O$ regresso de Ortov, Lajes do Pico, Companhia das llhas, col.

Azulcobalto/teatro, n. ${ }^{\circ}$ 3, 2013, $52 \mathrm{pp}$.

Ricardo Neves-Neves, A porta fechou-se e a casa era pequena, Lajes do Pico, Companhia das Ilhas, col. Azulcobalto/teatro, n. ${ }^{\circ} 4,2013,59$ pp.

Tiago Rodrigues, Peça romântica para um teatro fechado, Lajes do Pico, Companhia das llhas, col. Azulcobalto/teatro, n. ${ }^{\circ}$ 5, 2013, 56 pp.

Um texto dramático cumprirá a sua recepção apenas no momento em que chega à cena? Interpretado por actores, enquadrado por um espaço cénico e recebido por espectadores, parece ter nesse momento repetido em lugares e tempos vários a sua concretização plena, mas essa percepção, correspondendo a uma prática histórica que se mantém, não elide a natureza primeira de qualquer texto dramático, que é a de ser texto, precisamente.

A edição de teatro em Portugal tem sido, nestes anos recentes de fulgor editorial alimentado a best sellers e fenómenos de marketing, um resíduo quase invisivel, afastando dos hábitos de leitura o contacto com a dramaturgia a partir dessa natureza primeira e textual. A Cotovia, que tem catálogo teatral, para além dos Livrinhos de Teatro dos Artistas Unidos, a que se juntam edições assumidas por estruturas teatrais, por vezes em parceria com editoras, um ou outro título disperso por outros catálogos e pouco mais, sendo que no capítulo da disponibilização de textos fundamentais do corpus dramático português e universal, o descalabro é quase total (um leitor que procure, por exemplo, Gil Vicente ou Shakespeare na maioria das livrarias terá pouca sorte, ou nenhuma). A colecção Azulcobalto/teatro, da editora Companhia das Ilhas, é, também por isso, um ponto luminoso que importa não perder de vista. Dirigida por Rui Pina Coelho e Carlos Alberto Machado, a

Azulcobalto/teatro apresenta-se sob a forma de pequenos livrinhos, aparentados no formato com os Livrinhos de Teatro, e os primeiros cinco títulos correspondem a textos de dramaturgos portugueses contemporâneos que assinaram peças curtas, quase todas já representadas.

O regresso de Ortov, de Jaime Rocha, inclui dois textos em torno de uma mesma personagem ("O regresso de Ortov" e "O homem engessado"), compondo um díptico que se apoia em diálogos que assumem um certo absurdo de situação como eixo. As conversas entre Ortov e um polícia, primeiro, e entre Ortov e um homem engessado, depois, estruturam-se numa linguagem formalmente coloquial que revela, apesar disso, a sintaxe e o léxico de um idiolecto cuidado. É neste registo que os temas de conversa de Ortov, que partem da sua experiência para logo se confirmarem enquanto temas comuns a parte considerável do mundo contemporâneo, ganham corpo verbal. A emigração, a pobreza, o divórcio entre poder e cidadãos, a destruição ambiental e sobretudo a incomunicabilidade entre gente que vive lado a lado e na era da suposta comunicação global são temas que atravessam 0 regresso de Ortov sem tentações didácticas ou panfletárias. É o discurso, a linguagem e o modo como esta constrói o universo de Ortov, que conferem à leitura a força de um abalo que faz pensar.
Sara Figueiredo Costa estudou literatura e linguistica antes de chegar ao jornalismo. Actualmente é jornalista freelancer $\mathrm{e}$ crítica, com colaboração regular na Time Out, no Expresso e na Blimunda. 


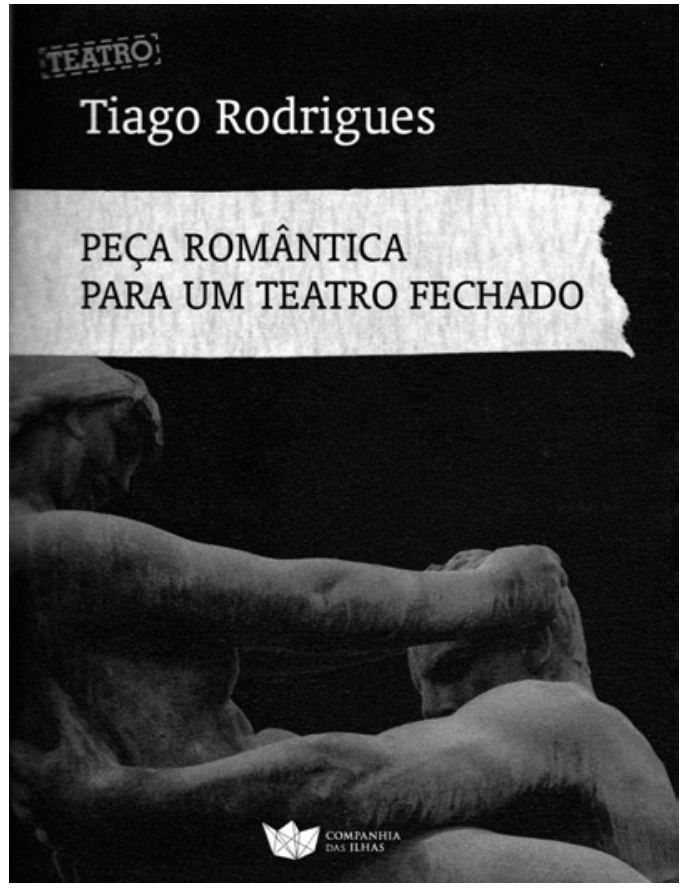

0 texto de Rui Pina Coelho enuncia um universo com linhas de força que o aproximam de Ortov, não na forma ou no contexto, mas nos temas e no modo de os abordar a partir do discurso do personagem. Ás vezes quase me acontecem coisas boas quando me ponho a falar sozinho é um monólogo com características formais que ecoam certas estruturas ritmicas do romanceiro tradicional, com repetições de uma frase, ou de uma variação, e onde um homem faz desfilar a sua história num discurso fragmentário e desordenado que acaba por elevar essa história a uma espécie de radiografia - desfocada e sem nunca querer ser sistemática - daquilo que chamariamos contemporaneidade, à falta de um termo menos disperso.

Ricardo Neves-Neves e Tiago Rodrigues criam peças onde a relação entre texto e cenário se revela fundamental, porque dessa relação nasce o contexto que permite a progressão das cenas e a construção do seu sentido. 0 cenário, no entanto, não é descrito com as especificações "clássicas", indicando espaços, adereços, perspectivas, mas antes construido a partir do discurso dos personagens. A porta fechou-se e a casa era pequena, de Ricardo NevesNeves, merecia ser lido a par com 0 problema da habitação, de Ruy Belo, num diálogo que assume o espaço doméstico como centro organizador de cada vida e que parte desse espaço para reconhecer o mundo, questionando-o. Pode reconhecer-se neste texto o manancial de pequenos dramas contemporâneos relativamente à habitação, do crédito ao preço por metro quadrado, mas é na relação da casa com o mundo que se encontram as linhas de leitura mais proficuas. Tiago Rodrigues, em Peça romântica para um teatro fechado, usa o espaço de uma sala teatra para reflectir sobre a memória, individual e colectiva, e os modos escorregadios com que a construimos, entre 0 que aconteceu e a vontade do que poderia ter acontecido. Dos cinco textos, este será o menos compativel com uma leitura extra-cénica, de mera fruição do texto, não por qualquer tibieza no trabalho da linguagem ou na construção de um espaço e de um tempo narrativos, mas porque as referências a múltiplas personagens com o

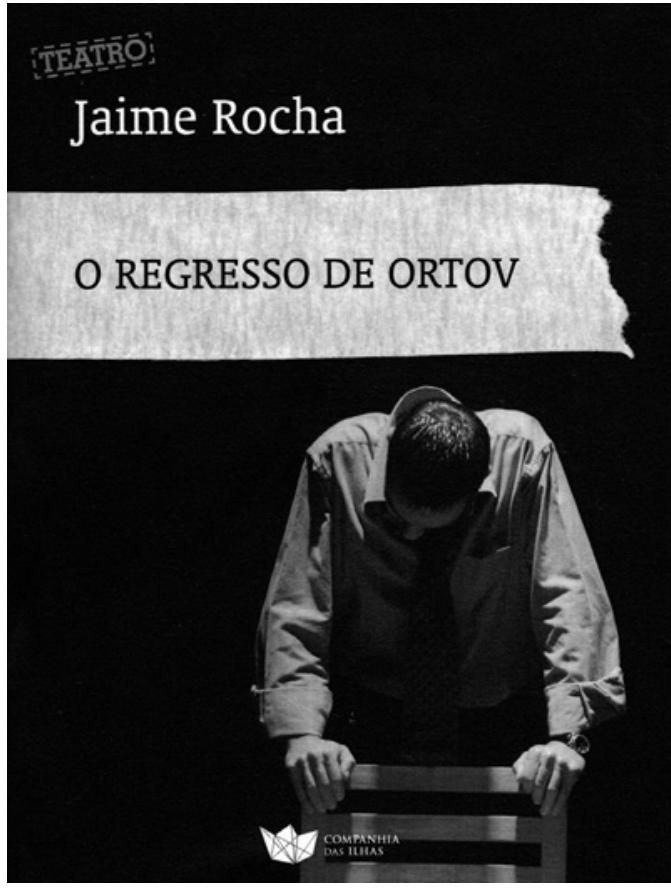

mesmo nome (Clara e Fernando 1, 2, 3, etc.) quebram a harmonia rítmica da leitura a partir do momento em que as falas se confundem na sequência.

Pedro Eiras reúne, em Bela Dona e Outros monólogos, cinco monólogos curtos onde a experimentação a partir da linguagem e das suas potencialidades é central para a construção de um universo. 0 primeiro monólogo, "Bela Dona", será aquele que mais pistas fornece sobre o ambiente físico em que decorre a acção, e igualmente o que menos parece depender de uma encenação para a sua completa fruição, mas qualquer dos textos se oferece como exercício de leitura recompensador.

Procurar uma linha comum aos cinco livros da Azulcobalto/teatro não é um exercício vazio ou forçado. Se cada texto se reveste de uma individualidade inabalável (estilística, temática e linguística), a possibilidade de verificar alguns pontos comuns permite olhar para estes livros como uma espécie de constelação. Lê-los com a atenção focada no texto, na matéria verbal e nas suas possibilidades semânticas, é um exercício que resulta na percepção de uma matéria partilhada, que poderíamos começar por classificar vagamente com a etiqueta da contemporaneidade, onde todos os discursos parecem incluir-se, mas que mais agudamente descreveríamos recorrendo à expressão camoniana do "desconcerto do mundo". A ruína de certos valores, que um dia foram dados como sólidos e inabaláveis, a atomização do conhecimento e das relações humanas numa nuvem virtual e infinita, que não permite bússolas, e a suspeita de que o crédito e o dinheiro virtual não deixarão pedra sobre pedra naquilo que conhecemos por sistema económico são azimutes possiveis para abordar esta constelação. Que o tema camoniano seja o fio que parece unir cinco textos tão diferentes não é revelador de qualquer aspecto datado nestes textos, nem de ausência de um olhar presente e, mais do que isso, capaz de se fazer intemporal, mas sobretudo da eterna actualidade de um modo tão antigo de olhar para o mundo e procurar entendê-lo. 